\title{
P. Falciparum Community Prevalence and Health Seeking Behaviors in Rural Sussundenga District, Mozambique
}

Dominique E Earland ( $\nabla$ earla001@umn.edu )

University of Minnesota School of Public Health https://orcid.org/0000-0001-5704-597X

Albino Francisco Bibe

Escola Secondaria de Sussundenga

Anísio Novela

Direccao Distrital de Saude de Sussundenga

João Ferrão

Instituto Superior de Ciencias de Educacao

Kelly M Searle

University of Minnesota School of Public Health

\section{Research Article}

Keywords: Health seeking behaviors, malaria prevalence

Posted Date: December 13th, 2021

DOI: https://doi.org/10.21203/rs.3.rs-1097255/v1

License: (c) (i) This work is licensed under a Creative Commons Attribution 4.0 International License. Read Full License 


\section{Abstract}

Background: The large-scale effectiveness of malaria control interventions is differential at international border settings with varying policies, such as that between Mozambique and Zimbabwe. Impacts of nationally directed malaria control interventions hinge on understanding malaria transmission and prevention at the community level along international borders. Thus far, few studies have focused on central Mozambique. Our aim was to describe community level $P$. falciparum transmission dynamics and health seeking behaviors among residents of Sussundenga, Mozambique, a rural village bordering Zimbabwe in Manica Province with high malaria incidence reported at the Sussundenga-Sede health center (RHC).

Methods: We conducted a cross-sectional community-based survey from December 2019 - February 2020. We used a random household sampling method, based on enumerated households from satellite imagery. All consenting participants completed a survey about malaria risk, prevention, and health seeking-behaviors, and received a $P$. falciparum malaria rapid diagnostic test (RDT).

Results: We enrolled 96 households with 358 individuals. The $P$. falciparum prevalence was 31.6\% (95\% $\mathrm{Cl}[26.6-36.5])$. Ninety-three percent of participants reported using the Sussundenga-Sede RHC for healthcare. Sixty-six percent of participants $(\mathrm{N}=233)$ experienced at least one malaria symptom in the past month, with self-reported fever most frequently reported (19.3\%). Of these, $176(76.5 \%)$ sought care in a health facility and $174(79 \%)$ received an RDT with $130(63 \%)$ positive results. Of those with a positive RDT, 127 (97\%) received Coartem ${ }^{\circledR}$. Following treatment, 123 (97\%) participants' symptoms resolved within a median of 3 days (IQR: 3-5) ranging from 2-14 days. In this high transmission setting, a high proportion of participants recognized malaria related symptoms then received a proper diagnostic test and treatment in a health facility.

Conclusions: Future interventions that leverage this health seeking behavior and strengthen health systems for community interventions will improve malaria control and inform the efficacy of potential interventions at this particular international border.

\section{Background}

The global estimated 229 million cases of malaria continues to disproportionately impact Sub-Saharan Africa (1). Mozambique is one of 29 countries that claim 95\% of global malaria cases. This high burden country reported $8,921,081$ malaria cases and 1,114 deaths in 2018 , which is about $4 \%$ of cases and deaths globally (2). Mozambique shares borders with six different countries including Tanzania, Malawi, Zambia, Zimbabwe, and South Africa, and Eswatini. All of these countries, except Malawi, have existing malaria elimination programs and interventions targeted at moving from successful malaria control to elimination $(3,4)$.

In the last few years collaborative malaria control and elimination efforts such as the Mozambique, South Africa, and Eswatini (MOSASWA) initiative in 2015 have demonstrated the utility of collaborative 
partnerships to address malaria morbidity and mortality(5). In 2018, the WHO introduced the High Burden to High Impact initiative which sought innovative country-led and strategic policies to reduce malaria death and disease among eleven high burden countries, including Mozambique(6). However, previous epidemiological studies evaluating malaria control measures have not focused on the central region of Mozambique, Manica province, despite the high malaria transmission and shared border with Zimbabwe(7,8).

Manica Province documented 821,775 malaria cases in 2019(9). Sussundenga district is one of nine districts in the province. This district contains 14 different rural health centers (RHCs) and has documented high annual incidence of malaria cases(10). Insecticide treated nets (ITNs) are the main preventive measure that is accessible to most households(10). Prompt diagnosis and treatment with Coartem ${ }^{\circledR}$ at a RHC is the standard of care for uncomplicated malaria illness.

The primary objective of this study was to describe community level $P$. falciparum transmission dynamics and health seeking behaviors in rural Sussundenga District in Manica Province, Mozambique, along the Zimbabwe border.

\section{Methods}

\section{Study Area}

The survey was conducted in Sussundenga village. Sussundenga village is approximately $70 \mathrm{~km}$ from the Provincial Capital of Chimoio, the capital of Manica Province, in central Mozambique (Figure 1). Sussundenga village is the district municipality of Sussundenga District and is a rural agrarian community with an approximate population of 19,112 and shares a border with Zimbabwe (2). From September to March, Manica Province has high temperatures and increased rainfall which contributes to the reported seasonal high malaria incidence. The main rural health center $(\mathrm{RHC})$ in the village is the Sussundenga-Sede health center, with 14 smaller RHCs located in the district. The primary malaria prevention intervention in the region are insecticide treated nets (ITNs) for households distributed through the antenatal care center.

\section{Study Design and Data Collection}

A cross-sectional community-based survey was administered from December 2019 to February 2020 in Sussundenga village. Satellite imagery was used to enumerate 2,889 households and a random household sampling method selected 125 households for screening and 100 households for enrollment to allow for potential misclassification of household structures and refusals. GPS coordinates were used to locate households for enrollment. Data collectors determined eligibility through a notification visit with the head of the household and assigned each household member a unique identifier.

Data collectors also obtained informed consent for all adult residents and parent/guardian permission for children between 3 months to 13 years old and assent for minors between 13 to 17 years old. 
Enrollment eligibility criteria was any full-time resident older than 3 months. After the notification visit, data collectors administered the electronic survey and recorded household GPS coordinates on a tablet computer using a REDCap ${ }^{\circledR}$ (Research Electronic Data Capture) mobile application. All participants older than 13 years old completed the survey and parents provided responses for children 3 months old to 13 years old.

A study nurse collected a finger prick blood sample and administered a malaria rapid diagnostic test (RDT). The Right Sign Malaria Pftest (Biotest, Hangzhou Biotest Biotech Co, China) was used in the study. All participants with positive results were referred to Sussundenga rural health center for confirmation of diagnosis and treatment. All symptoms reported to data collectors were self-reported based on malaria cases that occurred in the previous month. All data was collected and stored using the REDCap ${ }^{\circledR}$ server hosted at University of Minnesota School of Public Health and was treated confidentially $(11,12)$.

\section{Data Analyses}

All data analyses were performed using RStudio (version 2021.09.0+351) (13). Adults are considered older than 12 years old and children are less than 13 years old based on when they age out of pediatric care and into adult care in the health facility. School aged children were not included in the education level and malaria prevalence analysis to understand the association among adults. Community $P$. falciparum prevalence was determined by RDT results at the time of the survey. Pearson Chi square tests were used to compare the socio-demographic characteristics between malaria positive and negative individuals.

Health seeking behaviors were described as proportions with $95 \%$ confidence intervals. The health seeking variable was defined as the proportion of individuals with self-reported malaria symptoms within the past month that sought care at an RHC. The received RDT variable was defined as the proportion of malaria diagnoses by RDT among individuals with self-reported malaria symptoms within the past month. The received treatment variable was defined as the proportion of participants reporting malaria treatment by ACT (Coartem ${ }^{\circledR}$ ) among individuals with a positive malaria diagnosis by RDT in the past month.

The symptom resolution variable was defined as the proportion of malaria positive individuals who received treatment that self-reported symptom resolution. The days until symptoms resolved variable is a continuous variable that was self-reported based on an individual's most recent malaria infection. A violin plot was created to describe the number of days until symptoms resolved comparing all participants, adults, and children.

\section{Results}

\section{Socio-demographic characteristics}


The study enrolled 96 households with 358 individual household members. The age range was 1-80 years and children aged $1-12$ years old represented $36 \%$ of participants. The malaria prevalence was $31.6 \%$ (95\% Cl [26.6-36.5]). Adolescents aged 10-15 had the highest malaria prevalence compared to other age groups $(p<0.001)$ (Table 1$)$. Adults who completed less education (primary school only) had a higher malaria prevalence compared to those who completed higher education levels. ITN coverage was moderate with $65 \%$ of participants reporting sleeping under and ITN the previous night. There were not differences in use by age and ITNs were protective among those who reported use the previous night, with $53.7 \%$ prevalence compared to $69.1 \%$ prevalence among those who did not report ITN use the previous night $(p<0.01)$. There were no gender differences in malaria prevalence. There were not significant differences in malaria prevalence by occupation, although farmers had the highest malaria prevalence compared to other occupations. Ninety-three percent of participants reported using the Sussundenga-Sede RHC for their last episode of malaria symptoms. 
Table 1

Sociodemographic characteristics among malaria positive and negative

\begin{tabular}{|c|c|c|c|}
\hline & Malaria negative & Malaria positive & \\
\hline & $\%(\mathrm{~N})$ & $\%(\mathrm{~N})$ & \\
\hline Age & & & $\mathrm{P}<.001$ \\
\hline$<5$ years & $9.8(23)$ & 17.9(19) & \\
\hline $5-10$ years & 14.1(33.3) & $26.4(28)$ & \\
\hline 10 - 15 years & $12.0(28)$ & $18.9(20)$ & \\
\hline 16 - 20 years & $18.4(43)$ & 15.1(16) & \\
\hline 20 - 30 years & $20.5(48)$ & $9.4(10)$ & \\
\hline$>30$ years & 25.2(59) & $12.3(13)$ & \\
\hline Sex & & & $\mathrm{P}=.84$ \\
\hline Male & 43.2(99) & $44.3(47)$ & \\
\hline Female & $56.8(130)$ & $55.7(59)$ & \\
\hline Employment & & & $P=.39$ \\
\hline Farmer & $56.7(38)$ & $81(17)$ & \\
\hline Miner & $1.5(1)$ & (0) & \\
\hline Health worker & $1.5(1)$ & $(0)$ & \\
\hline Teacher & $22.4(15)$ & $4.8(1)$ & \\
\hline Coroner & $1.5(1)$ & $0(0)$ & \\
\hline Business Owner & $16.4(11)$ & 14.2(3) & \\
\hline Education & & & $\mathrm{P}<.01$ \\
\hline Grades 1-5 & $7.5(8)$ & $6(14)$ & \\
\hline Grades 6-7 & $7.5(8)$ & $12.8(30)$ & \\
\hline Grades 8-10 & $16(17)$ & 26.1(61) & \\
\hline Grades 11-12 & $8.5(9)$ & 17.1(40) & \\
\hline University & $0(0)$ & $2.6(2.6)$ & \\
\hline N/A & $60.5(64)$ & $35.4(83)$ & \\
\hline Bed Net Usage & & & $P<.01$ \\
\hline
\end{tabular}




\begin{tabular}{|lll|}
\hline & Malaria negative & Malaria positive \\
\hline No & $30.9(72)$ & $46.3(50)$ \\
\hline Yes & $69.1(161)$ & $53.7(58)$ \\
\hline Regular Health Center & & \\
\hline Sussundenga-Sede & $91.9(215)$ & $97.3(105)$ \\
\hline Munhinga & $1.3(3)$ & $0.9(1)$ \\
\hline Dombe & $0(0)$ & $0.9(1)$ \\
\hline Muôha & $0.4(1)$ & $0(0)$ \\
\hline Rotanda & $0.4(1)$ & $0(0)$ \\
\hline Other & $6(14)$ & $0.9(1)$ \\
\hline
\end{tabular}

\section{Health seeking characteristics and timeline}

Sixty-six percent of participants $(\mathrm{N}=233)$ experienced at least one malaria related symptom in the past month, with self-reported fever most frequently reported (19.3\%). Of the participants that reported symptoms, 75.1\% (95\% Cl [70-80.9]) sought care at a health facility and 62.2\% (95\% Cl [56.2-68.8 ]) received an RDT. Ninety-eight percent of RDT positive participants received Coartem ${ }^{\circledR}$, the standard of care for uncomplicated malaria in Mozambique, and 97.1\% (95\% Cl [91. 99.2 ]) of participants treated with Coartem ${ }^{\circledR}$ had all symptoms resolved. Of the four participants that did not receive Coartem ${ }^{\circledR}$, one participant experienced severe malaria and received quinine, and the remaining participants did not receive the standard of care.

Three participants (2.9\%), which were school-aged children, reported unresolved symptoms after receiving the standard of care at the Sussundenga-Sede RHC (diagnosis with an RDT and treatment with Coartem $\left.{ }^{\circledR}\right)$, and one individual continued to be malaria positive at the time of the survey. Four (3.3\%) participants had a malaria related hospitalization after self-reported symptoms within the last month. Two of the individuals with severe disease requiring hospitalization were adults older than 40 years and the other two individuals were children.

\section{Efficacy and Access to Care}

Median time until reported symptoms resolved was 3 days (IQR: 3-5) and ranged from 2-14 days. Figure 4 shows the distribution of days until reported symptoms resolved among all participants, children, and adults. There were no significant differences in median days until symptoms resolved between children and adults. Nearly all (97.7\%) participants preferred the Sussundenga-Sede RHC for care, the majority reported this preference because it was close to their home (94.8\%). There was no difference in the reported preference for $\mathrm{RHC}$ by rainy and dry season. 


\section{Discussion}

This research estimated the community malaria prevalence and described health seeking behaviors of households in Sussundenga village. Findings from this study indicate a high degree of treatment seeking behaviors among children and adults, specifically at the Sussundenga-Sede rural health center. The majority of individuals with symptoms sought treatment, received an RDT, and obtained standard treatment $\left(\right.$ Coartem $\left.{ }^{\circledR}\right)$. Sussundenga residents who received treatment were likely to resolve their symptoms a short time after seeking treatment. Cassey et al described the increased health seeking capacity of rural households in Manica province in comparison to Maputo city(14). The high level of health seeking behaviors could be explained by the close proximity of the largest rural health center in the village, as several studies have demonstrated the association of shorter traveling distance and utilization of malaria healthcare(14-16).

The 2018 Mozambique Malaria Indicator Survey similarly reported a high malaria prevalence in Manica province among children under five (48\%), the third highest in Mozambique(10). In Sussundenga village the malaria prevalence was elevated among children and adults in contrast to the effective management of malaria cases among households in our study. Expansion of the thousands of Agentes Polivalentes Elementares (APEs) within the national integrated community case management (iCCM) strategy could increase coverage and access to treatment $(17,18)$. Our study demonstrated persistent health seeking behaviors among households suggesting a high degree of trust with the government run healthcare system. This suggests that an intervention like utilizing APEs could be effective, as APEs require community trust to facilitate their uptake in communities and provide treatment for rural populations(19). Districts in Southern Mozambique involved in elimination programs receive monthly electronic reports about malaria cases and other clinical metrics from District health facilities and APEs to strengthen their epidemiological surveillance system(20,21). Additional resources for APEs to delivery ITNs and treat asymptomatic malaria cases could reduce transmission in high burden settings like Sussundenga district $(22,23)$.

There were several limitations to this study, the first being the cross-sectional design which hinders observing the potential for changing health seeking behaviors over time. Our study relied on self-reported metrics and lacked information directly from rural health centers. Additional understanding of treatment compliance information and direct information from healthcare professionals at the RHC about patient treatment compliance, available resources, and other quality care metrics could further explain our findings(22). Additionally, with self-reported responses there is the potential that recall bias could have impacted the accuracy of responses about information surrounding previous malaria symptoms and care.

Prior studies in Manica province determined rural regions have increased prevalence in comparison to urban areas(10), but have not yet quantified the community prevalence in the majority of these rural regions. Few studies have determined the community prevalence of regions in Sussundenga district, especially Sussundenga village. Our study found households promptly sought care to treat their malaria 
symptoms, which suggests that the RHCs and individual households are strengths to incorporate into future studies and interventions. Additional efforts to understand drivers of community prevalence in well-resourced, high burden areas could inform innovative community driven malaria prevention and vector control measures.

\section{Conclusion}

In this high transmission setting, a majority of participants recognized malaria related symptoms and received a proper diagnostic test and treatment in a health facility. Despite the uptake of treatment to resolve symptoms and utilization of ITNs, the high community prevalence does not reflect the high degree of health seeking behavior. This suggests additional prevention methods like APEs are necessary to address the malaria burden in the district. Future interventions that leverage health seeking behavior and strengthen health systems for community interventions will improve malaria control and inform the efficacy of potential interventions at international borders.

\section{Abbreviations}

APE Community Health Workers

\section{Declarations}

\section{Ethical Approval and consent to participate}

This study was reviewed and approved by the Research and Ethics Committee, University of Minnesota IRB [IRB number] and the Comissão Nacional de Bioética em Saúde (CNBS) from the Ministry of Health of Mozambique, approval number 560/CNBS/19.

\section{Consent for Publication}

Not applicable

\section{Availability of data and materials}

All data generated or analyzed during this study are included in this published article.

Competing Interests

The authors declare that they have no competing interests

Funding 
This study was funded through a SEED grant from the University of Minnesota Center for Global Health and Social Responsibility (CGHSR).

\section{Authors Contributions}

D.E and K.S. contributed to the study design, project implementation, analysis of results, and writing of the manuscript.

A.B. contributed to project implementation and data collection.

A.N. contributed to project implementation and sample collection as the study nurse.

J.F. contributed to the study design and project implementation.

\section{Acknowledgements}

We would like to acknowledge the study participants and staff in Mozambique as well as our funding sources.

\section{References}

1. World malaria report 2020: 20 years of global progress and challenges [Internet]. Geneva: World Health Organization; 2020. Available from: https://www.who.int/publications/i/item/9789240015791

2. Mozambique: Country Profiles [Internet]. World Health Organization; 2019. Available from: https://www.who.int/gho/countries/moz/country_profiles/en/

3. Moss WJ, Norris DE, Mharakurwa S, Scott A, Mulenga M, Mason PR, et al. Challenges and prospects for malaria elimination in the Southern Africa region. Tackling Malar End Game Reg Needs Chall Success Malar Elimin. 2012 Mar 1;121(3):207-11.

4. Finda MF, Christofides N, Lezaun J, Tarimo B, Chaki P, Kelly AH, et al. Opinions of key stakeholders on alternative interventions for malaria control and elimination in Tanzania. Malar J. 2020 Apr 23;19(1):164.

5. MOSASWA strategic plan 2016-2020. Maputo: MOSASWA; 2015.

6. High Burden to high impact: a targeted malaria response. Geneva: World Health Organization; 2018.

7. Aide P, Candrinho B, Galatas B, Munguambe K, Guinovart C, Luis F, et al. Setting the scene and generating evidence for malaria elimination in Southern Mozambique. Malar J. 2019 Jun 6;18(1):190.

8. Plucinski MM, Candrinho B, Chambe G, Muchanga J, Muguande O, Matsinhe G, et al. Multiplex serology for impact evaluation of bed net distribution on burden of lymphatic filariasis and four species of human malaria in northern Mozambique. PLoS Negl Trop Dis. 2018 Feb 14;12(2):e0006278. 
9. Relatório do Primeiro Semestre 2020. Programa Nacional de Controlo da Malaria. Direcção Provincial de Saúde de Manica; 2020.

10. Instituto Nacional de Saúde/INS, Instituto Nacional de Estatistica/INE, Programa Nacional de Controlo da Malaria/PNCM, ICF. Mozambique Inquérito Nacional sobre Indicadores de Malaria (IIM)2018 [Internet]. Maputo, Mozambique: INS/Mozambique, INE, PNCM, ICF; 2019. Available from: http://dhsprogram.com/pubs/pdf/MIS33/MIS33.pdf

11. Harris PA, Taylor R, Thielke R, Payne J, Gonzalez N, Conde JG. Research electronic data capture (REDCap)-A metadata-driven methodology and workflow process for providing translational research informatics support. J Biomed Inform. 2009 Apr 1;42(2):377-81.

12. Harris PA, Taylor R, Minor BL, Elliott V, Fernandez M, O'Neal L, et al. The REDCap consortium: Building an international community of software platform partners. J Biomed Inform. 2019/05/09 ed. 2019 Jul;95:103208-103208.

13. RStudio Team. Studio: Integrated Development for R. RStudio [Internet]. Boston, MA; 2020. Available from: http://www.rstudio.com/

14. Cassy A, Saifodine A, Candrinho B, Martins M do R, da Cunha S, Pereira FM, et al. Care-seeking behaviour and treatment practices for malaria in children under 5 years in Mozambique: a secondary analysis of 2011 DHS and 2015 IMASIDA datasets. Malar J. 2019 Apr 2;18(1):115.

15. Treleaven E, Whidden C, Cole F, Kayentao K, Traoré MB, Diakité D, et al. Relationship between symptoms, barriers to care and healthcare utilisation among children under five in rural Mali. Trop Med Int Health. 2021 Aug 1;26(8):943-52.

16. Mochida K, Nonaka D, Wamulume J, Kobayashi J. Supply-Side Barriers to the Use of Public Healthcare Facilities for Childhood Illness Care in Rural Zambia: A Cross-Sectional Study Linking Data from a Healthcare Facility Census to a Household Survey. Int J Environ Res Public Health. 2021 May 19;18(10):5409.

17. Chilundo BG, Cliff JL, Mariano AR, Rodríguez DC, George A. Relaunch of the official community health worker programme in Mozambique: is there a sustainable basis for iCCM policy? Health Policy Plan. 2015 Dec;30 Suppl 2(Suppl 2):ii54-64.

18. National Malaria Control Program Malaria Strategic Plan 2017-2022 [Internet]. Mozambique: Ministry of Health, WHO, and PMI; 2017. Available from: https://pdf.usaid.gov/pdf_docs/PA00W8CM.pdf

19. Young M, Wolfheim C, Marsh DR, Hammamy D. World Health Organization/United Nations Children's Fund joint statement on integrated community case management: an equity-focused strategy to improve access to essential treatment services for children. Am J Trop Med Hyg. 2012 Nov;87(5 Suppl):6-10.

20. Aide P, Candrinho B, Galatas B, Munguambe K, Guinovart C, Luis F, et al. Setting the scene and generating evidence for malaria elimination in Southern Mozambique. Malar J. 2019 Jun 6;18(1):190.

21. Moonasar D, Maharaj R, Kunene S, Candrinho B, Saute F, Ntshalintshali N, et al. Towards malaria elimination in the MOSASWA (Mozambique, South Africa and Swaziland) region. Malar J. 2016 Aug 
18;15(1):419.

22. Candrinho B, Plucinski MM, Colborn JM, da Silva M, Mathe G, Dimene M, et al. Quality of malaria services offered in public health facilities in three provinces of Mozambique: a cross-sectional study. Malar J. 2019 May 6;18(1):162.

23. Rodrigues EDH, Zulliger R. Mozambique's Agentes Polivalentes Elementares. Health People Natl Community Health Work Programs Afghan Zimb. 2020;247.

\section{Figures}

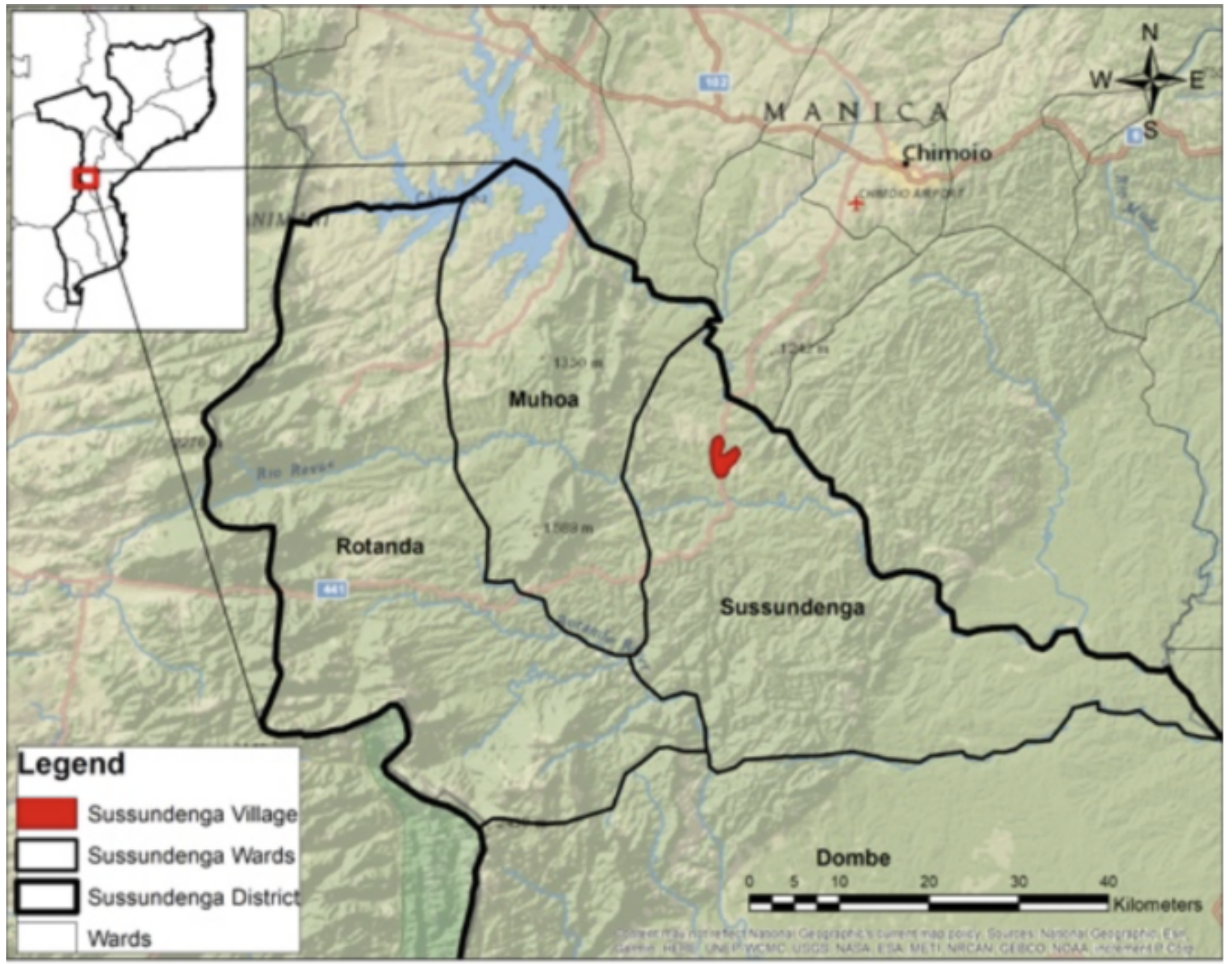

\section{Figure 1}

Map of Sussundenga Village 


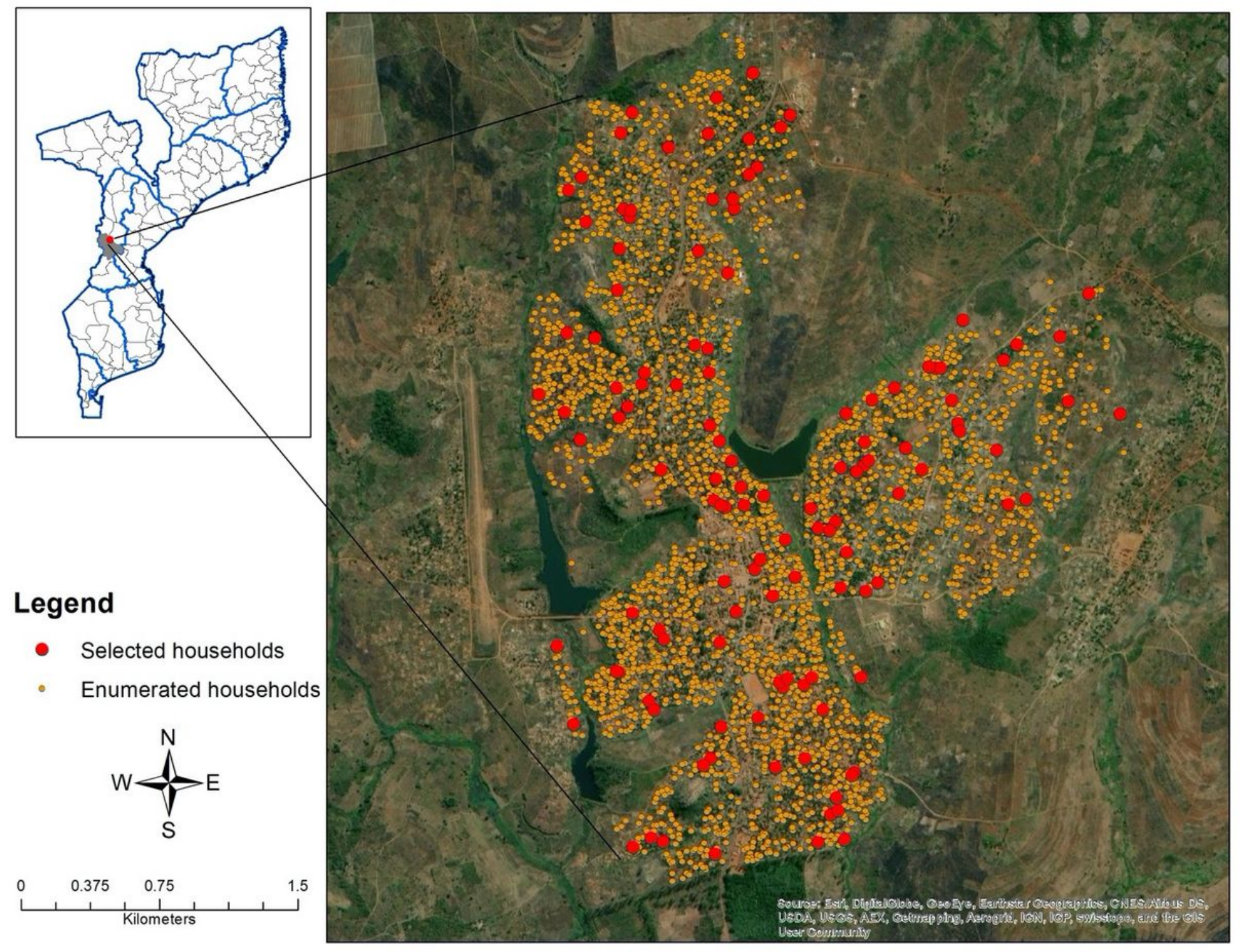

Figure 2

Map of enumerated and selected households 


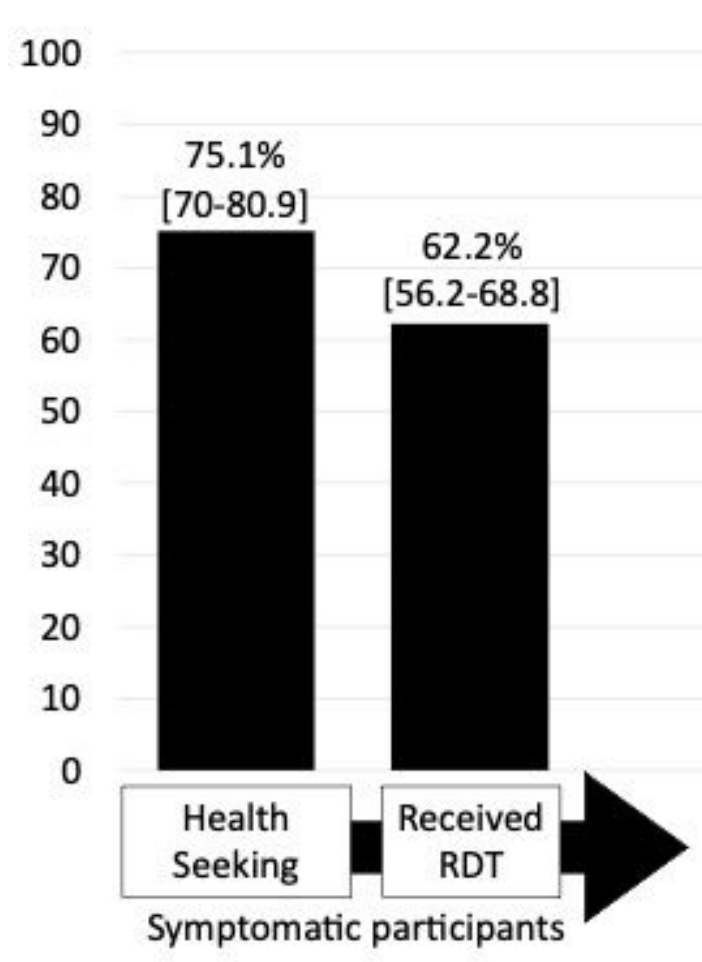

$\begin{array}{cc}96.2 \% & 97.1 \% \\ {[90.1-98.8]} & {[91-99.2]}\end{array}$

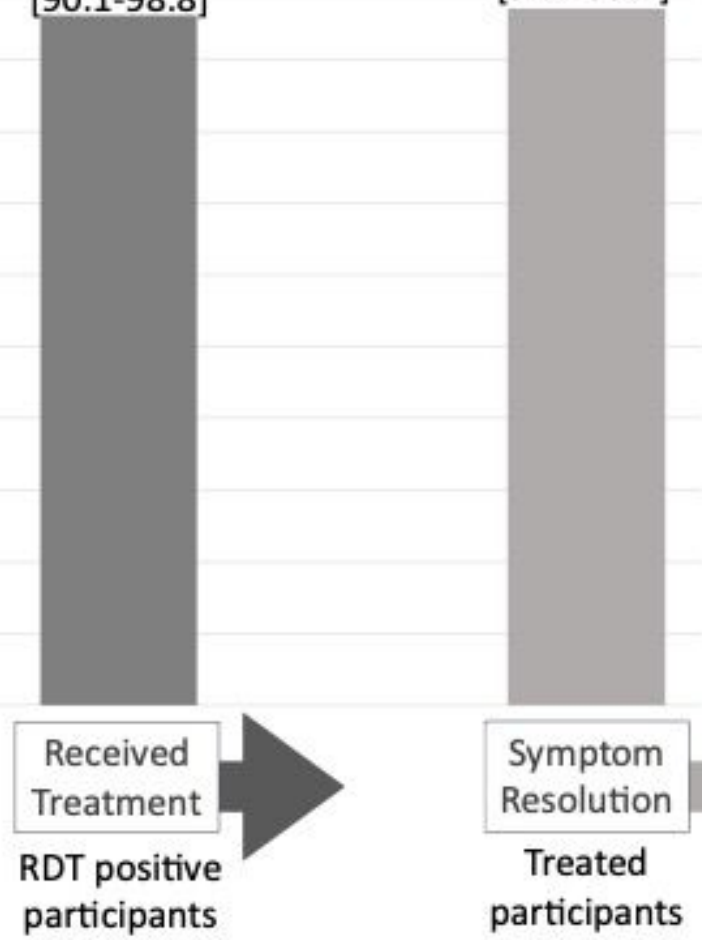

Figure 3

Health Seeking among symptomatic, RDT positive, and Coartem ${ }^{\circledR}$ treated participants

\section{Image not available with this version}

\section{Figure 4}

This image is not available with this version. 